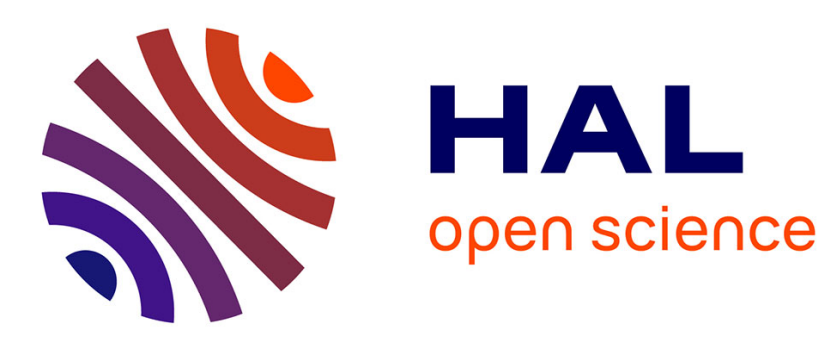

\title{
Use of various device geometries to improve the performance of CdTe detectors
}

\author{
K. Zanio
}

\section{To cite this version:}

K. Zanio. Use of various device geometries to improve the performance of CdTe detectors. Revue de Physique Appliquée, 1977, 12 (2), pp.343-347. 10.1051/rphysap:01977001202034300 . jpa-00244170

\section{HAL Id: jpa-00244170 https://hal.science/jpa-00244170}

Submitted on 1 Jan 1977

HAL is a multi-disciplinary open access archive for the deposit and dissemination of scientific research documents, whether they are published or not. The documents may come from teaching and research institutions in France or abroad, or from public or private research centers.
L'archive ouverte pluridisciplinaire HAL, est destinée au dépôt et à la diffusion de documents scientifiques de niveau recherche, publiés ou non, émanant des établissements d'enseignement et de recherche français ou étrangers, des laboratoires publics ou privés. 


\title{
USE OF VARIOUS DEVICE GEOMETRIES TO IMPROVE THE PERFORMANCE OF CdTe DETECTORS (*)
}

\author{
K. ZANIO \\ Hughes Research Laboratories 3011 Malibu Canyon Road Malibu, California 90265, U. S. A.
}

\begin{abstract}
Résumé. - Des détecteurs nucléaires ont été réalisés à partir de tellurure de cadmium semiisolant $\left(\rho>10^{7} \Omega . \mathrm{cm}\right)$. Différentes formes géométriques ont été essayées en vue de tirer profit des produits $\mu \tau^{+}$plus importants pour les électrons $\left(6-10 \times 10^{-4} \mathrm{~cm}^{2} / \mathrm{V}\right)$ que pour les trous $\left(5 \times 10^{-6} \mathrm{~cm}^{2} / \mathrm{V}\right)$ tout en tenant compte des longueurs d'absorption variables suivant l'énergie des photons. Dans le cas de photons $\mathrm{X}$, des structures planes dont les aires peuvent atteindre $3 \mathrm{~cm}^{2}$ ont été développées. Pour des photons d'énergie plus élevée, des structures hémisphériques, dans lesquelles les champs électriques ne sont pas constants, donnent les meilleurs résultats. On a étudié leur possibilité d'emploi en imagerie nucléaire en associant plusieurs compteurs. Lorsque les applications envisagées nécessitent des efficacités de détection importantes sous un faible volume des formes parallélépipédiqus sont préférables. Nous avons mis au point de tels détecteurs de dimensions $3 \times 7 \times 20 \mathrm{~mm}$ qui sont employés dans les mesures d'usure de capsules spatiales au moment de leur rentrée dans l'atmosphère.
\end{abstract}

Abstract. - Cadmium telluride detectors were fabricated from semi-insulating material $\left(\rho>10^{7} \Omega . \mathrm{cm}\right)$ with different geometries so as to take advantages of the superior mobilitytrapping time products of electrons $\left(\mu_{\mathrm{e}} \tau_{\mathrm{e}}{ }^{+}=6-10 \times 10^{-4} \mathrm{~cm}^{2} / \mathrm{V}\right)$ as compared to those of holes $\left(\mu_{\mathrm{h}} \tau_{\mathrm{h}}{ }^{+} \approx 5 \times 10^{-6} \mathrm{~cm}^{2} / \mathrm{V}\right)$ and suit different ranges of photon energies. In the case of X-ray detectors, plane parallel devices were fabricated with active areas up to $3 \mathrm{~cm}^{2}$. For the case of high energy more penetrating radiation, cube shaped detectors, having nonuniform electric fields, were fabricated. Arrays were also made from such cubes to evaluate their potential use in imaging applications at room temperature. Where a small frontal area but high efficiency is required, such as in ablation studies for reentry vehicles, bar-shaped detectors, $3 \mathrm{~mm} \times 7 \mathrm{~mm}$ and up to $2 \mathrm{~cm}$ in length are appropriate and were also fabricated.

1. Introduction. - The most direct method of increasing the resolution of $\mathrm{CdTe}$ gamma ray and $\mathrm{x}$-ray detectors is to increase the charge collection efficiency. This implies increasing the mobilitytrapping time product $\left(\mu \tau^{+}\right)$of both electrons and holes. Because of the expense in preparing higher purity starting materials and upgrading processing techniques significant increases in the trapping times are becoming increasingly more difficult to achieve. An alternative and important approach to improve the resolution is to improve the uniformity of charge collection. Uniform charge collection implies more uniform concentrations of electron and hole traps. Uniform charge collection also implies choosing an optimum device configuration for a specific photon energy and set of transport properties. Besides $\mu_{\mathrm{e}}, \mu_{\mathrm{h}}, \tau_{\mathrm{e}}^{+}$and $\tau_{\mathrm{h}}^{+}$, the electric field $[E(x)]$ and the density of electron hole pairs generated by the photon flux $[n(x)]$ determine the resolution [1]. In this paper device configurations are described which optimize the resolution of X-ray and gamma ray detectors fabricated from semi-insulating $\left(\rho>10^{7} \Omega . \mathrm{cm}\right)$ In-

(*) Work supported by ERDA, Division of Environmental and Biomedical Research. doped CdTe. Devices do not polarize as those having blocking contacts and fabricated from Cl-doped material grown by the travelling heater method.

2. X-ray detectors. - For $60 \mathrm{keV}$ photons the half thickness in CdTe is about $120 \mu \mathrm{m}$. For X-rays it is therefore not imperative to use semi-insulating CdTe, since the photon half thickness is small and comparable to the depletion thickness of surface barrier detectors fabricated from moderate resistivity material. Significant charge transport is due to both electrons and holes since the drift lengths of both carriers are comparable to or greater than the depletion width. Using gold surface barriers on n-type material, Dabrowski et al. [2] obtained resolutions of $1.7 \mathrm{keV}$ and $1.1 \mathrm{keV}$ at room temperature for $59.6 \mathrm{keV}$ gamma rays from ${ }^{241} \mathrm{Am}$ and $5.9 \mathrm{keV}$ X-rays from ${ }^{55} \mathrm{Fe}$. These results were obtained with detectors having active areas of about $3 \mathrm{~mm}^{2}$. X-ray detectors fabricated from moderate resistivity material may not suffice where efficiency is at a premium. When $\mathrm{cm}^{2}$ areas are required and high energy $X$-rays are used the use of high resistivity material may be more practical and even imperative.

$\mathrm{X}$-ray detectors were prepared here by polishing wafers up to $4 \mathrm{~cm}^{2}$ in area and $2 \mathrm{~mm}$ thick with 
alundum powder and painting the side serving as the negative electrode with aquadag. The active area of the detector was defined with a $\mathrm{Pb}$ collimator. The positive electrode was aquadag. The area of the dot was comparable to that defined by the collimator. Scans with collimated beams and efficiency measurements with ${ }^{241} \mathrm{Am}$ showed the areas defined by the collimation to be at least $90 \%$ active. Radiation is incident upon the negative electrode to take advantage of the superior transport properties of electrons (Fig. 1a). When the electrode separation is of the order of a few millimeters in semi-insulating material charge collection is characteristic of a single carrier. In general $\mu_{\mathrm{e}} \tau_{\mathrm{e}}^{+} / \mu_{\mathrm{h}} \tau_{\mathrm{h}}^{+}$is greater than one due to the larger mobility of electrons. Even if the opposite case prevailed it might still be advantageous to utilize electron collection due to its shorter transit time and consequently to allow the flexibility of using a shorter pulse shaping time to reduce noise, which is more important at lower photon energies. Figure $2 a$ shows a ${ }^{129}$ I spectrum taken with a detector fabricated



(a)

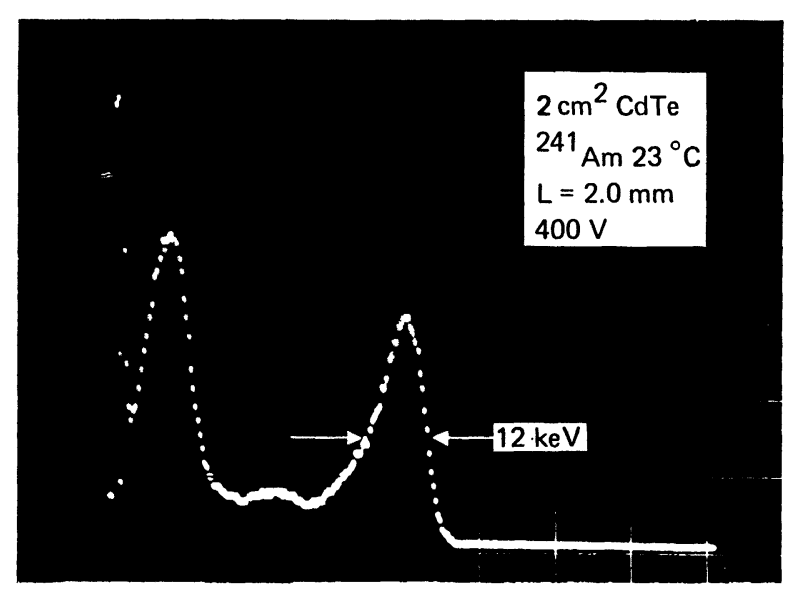

(c)
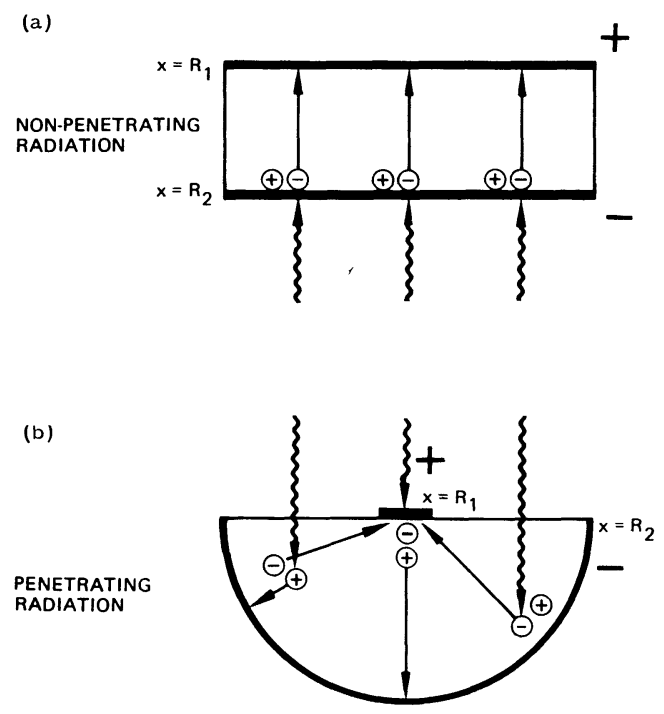

FIG. 1. - Preferred device geometry for, (a) non-penetrating and $(b)$ penetrating phonons in semi-insulating CdTe where the electron $\mu \tau^{+}$products are much larger than the hole $\mu \tau^{+}$ products.



(b)



(d)

FIG. 2. - X-ray spectra characteristic of electron transport in semi-insulating CdTe. 
from semi-insulating material and for electrons incident upon the negative electrode [3]. The $\mu \tau^{+}$ product for electrons is about $8 \times 10^{-4} \mathrm{~cm}^{2} / \mathrm{V}$ and the $\mu \tau^{+}$product for holes is about $5 \times 10^{-6} \mathrm{~cm}^{2} / \mathrm{V}$. The device is operated at $0{ }^{\circ} \mathrm{C}$ and has an active area of about $10 \mathrm{~mm}^{2}$. The resolution of the $28.6 \mathrm{keV}$ peak (FWHM) is $1.9 \mathrm{keV}$, with contributions to the width from trapping and current noise being comparable. Upon increasing the active area to $1 \mathrm{~cm}^{2}$ the resolution decreases. For the $59.6 \mathrm{keV}$ photons from ${ }^{241} \mathrm{Am}$ the resolution for a device having an area of $1 \mathrm{~cm}^{2}$ is $5 \mathrm{keV}$ (FWHM). There is some penetration of the $60 \mathrm{keV}$ photons in the sample. Since the ratio of the drift length to the electrode separation for holes is only 0.1 , there is incomplete charge collection from holes and photopeak tailing. Both the 14 and $17 \mathrm{keV}$ peaks are clearly resolved. Tailing would not be expected at these lower energies since the half thickness of these photons is only about $15 \mu \mathrm{m}$. Increasing the device area to $2 \mathrm{~cm}^{2}$ results in an increase in the thermal current and broadening of the $59.6 \mathrm{keV}$ peak. The 14 and $17 \mathrm{keV}$ peaks are not separated. After thinning the device to $0.7 \mathrm{~mm}$ the $59.6 \mathrm{keV}$ peak shows severe tailing because charge collection of holes is even more incomplete. (The detector bias was reduced to $100 \mathrm{~V}$ to achieve the same peak position and reduce the current noise). Detectors with active areas up to $3 \mathrm{~cm}^{2}$ were fabricated. Although the resolution deteriorated even further photopeaks were still apparent at room temperature with ${ }^{129} \mathrm{I}$ for biases as low as $10 \mathrm{~V}$. These results indicate that $\mathrm{X}$-ray spectra can be achieved over large areas with only electron collection. However, this requires that the ratio of the photon half thickness to the electrode separation be small. In these studies tailing only became apparent for ratios greater than 0.05 .

3. Gamma ray detectors. - 3.1 HEMISPHERICAL DETECTORS. - For more penetrating photons where the half thickness of the photon is comparable to or greater than the electrode separation, better resolution is possible by choosing an optimum field shape for a given set of transport parameters. The basic idea is to increase the electric field in the region of the crystal where trapping is excessive. For example, if the $\mu \tau^{+}$product of holes is much less than that of electrons more trapping would occur at the positive electrode. A higher field at the positive electrode would increase the drift velocity of holes in this region and result in more uniform charge collection. By fabricating the device in so the shape of a hemisphere the field is contoured to that a larger electric field occurs at the smaller positive electrode, as in figure $1 b$. For this geometry the density of electronhole pairs is proportional to the radius square. An additional consequence of this geometry is that the concentration of holes generated at the positive electrode and available for charge transport is small and the bulk of the charge transport is due to elec- trons. Using this approach, detectors $1 / 2 \mathrm{~cm}^{3}$ with resolution as low as $6-1 / 2 \%$ (FWHM) at $662 \mathrm{keV}$ have been fabricated [4].

Just what volumes and resolutions can ultimately be attained by this technique is not clear. Resolution near $4 \%$ have been attained for smaller devices. In fact, if fluctuations in the trap concentration are not considered, calculations show that resolutions of a few $\mathrm{keV}$ are possible with microsecond trapping times. Estimates of the maximum trap concentration allowed to attain $1 \mathrm{keV}$ resolution have also been made in plane parallel devices $[5,6]$. Such estimates are difficult to rely on since the uniformity of the material is not considered. One method to estimate the transport properties required of larger devices which would have the same resolution of smaller devices is by scaling ; i. e., by assuming that if uniformity can be maintained, comparable resolutions require comparable $\tau^{+} / T_{\mathrm{R}}$ ratios. Siffert et al. [7] obtained approximately $2 \%$ resolution with ${ }^{137} \mathrm{Cs}$ for a $0.5 \mathrm{~mm}$ thick and approximately $5 \mathrm{~mm}^{3}$ volume device. These results are characteristic of $\mathrm{Cl}$-doped material which

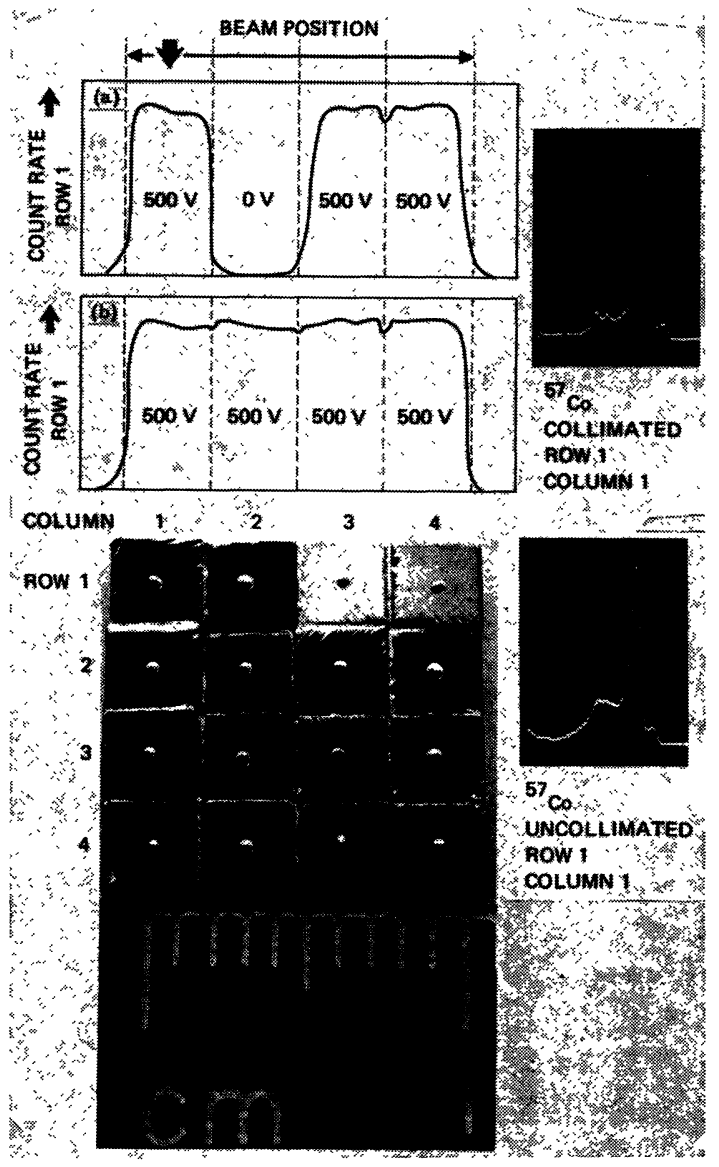

Fig. 3. - (Bottom) A $4 \times 4$ matrix of $(3 \mathrm{~mm} \times 3 \mathrm{~mm} \times 2 \mathrm{~mm})$ CdTe detectors each element utilizing field shaping to improve resolution. (Top) Scan with a $1 / 2 \mathrm{~mm}$ diameter $57 \mathrm{Co}$ beam across a row (a) with four elements operated at $500 \mathrm{~V}$ and (b) with only elements 1,3 and 4 operated. Included on the righthand side are $57 \mathrm{Co}$ spectra from a detector element using (top) the collimated beam and (bottom) from an uncollimated point source. 
has a $\mu \tau^{+}$product for holes in the $10^{-5}-10^{-4} \mathrm{~cm}^{2} / \mathrm{V}$ range and a $\mu \tau^{+}$product for electrons of about $10^{-3} \mathrm{~cm}^{2} / \mathrm{V}$ (Ref. [8 and 9]). The $\tau^{+} / T_{\mathrm{R}}$ ratio for electrons and holes are approximately 100 and 10 , respectively. Therefore, the resolution is limited by hole trapping. (In the simplest approximation values of 10 and 100 for $\tau^{+} / T_{\mathrm{R}}$ correspond to collection efficiencies of about $95 \%$ and $99 \%$, respectively.) Assuming the volume scales as the cube of the electrode separation, an electrode spacing of about $2.5 \mathrm{~mm}$ is necessary to achieve the $1 / 2 \mathrm{~cm}^{3}$ volume. For a $1000 \mathrm{~V}$ bias this predicts that a $\mu \tau^{+}$product of about $10^{-3} \mathrm{~cm}^{2} / \mathrm{s}$ or an order of magnitude decrease in the concentration of hole traps is required to obtain the same collection efficiency, and presumably the same resolution as the smaller plane parallel device. This approach is optimistic, since in the $1 / 2 \mathrm{~cm}^{3}$ hemispherical device only $6-1 / 2 \%$ resolution for ${ }^{137} \mathrm{Cs}$ has been attained although the $\mu \tau^{+}$product for the important carrier, electrons, is $10^{-3} \mathrm{~cm}^{2} / \mathrm{V}$. (The transport properties for holes in the hemispherical devices are not an important consideration as long as their $\mu \tau^{+}$products are at least an order of magnitude less than that of the electrons).

A more realistic approach to attain a $2 \%$ resolution in a larger volume device is to consider the uniformity problem to be more severe in the larger volume devices and to require a $\mu \tau^{+}$product of at least $10^{-2} \mathrm{~cm}^{2} / \mathrm{V}$ for both electrons and holes in the plane



FIG. 4. - (Bottom) Schematic of sealed ${ }^{57}$ Co source placed on $\mathrm{Pb}$ collimator, CdTe detector array. (Top) Plot of count rates measured through each of the four collimators in rows 3 and 4. The envelope is a scan of the source through each of these sections with a single collimated detector. parallel device and $10^{-2} \mathrm{~cm}^{2} / \mathrm{V}$ for electrons in the hemispherical device.

An alternative approach to increase the volume is to stack smaller detectors in an array. Such a configuration also allows the possibility of imaging. Figure 3 shows a $4 \times 4$ matrix of $(3 \mathrm{~mm} \times 3 \mathrm{~mm} \times 2 \mathrm{~mm})$ CdTe detectors. After individual elements were fabricated by polishing, aquadag was painted on five sides to form the negative electrode. A $1 \mathrm{~mm}$ dot of aquadag was painted on the large remaining face for the positive electrode. The negative electrodes of the individual elements were joined in a matrix with silver epoxy. Line scans across rows with colli-

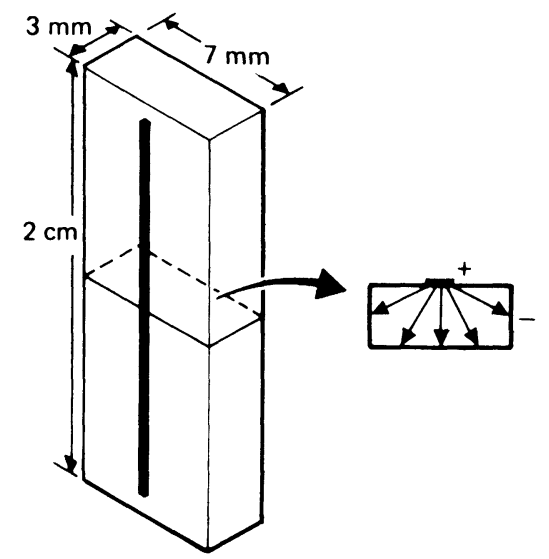

CdTe DETECTOR


FIG. 5. - (Top) Bar-shaped CdTe detector using a narrow strip as the positive electrode to shape the electric field and enhance resolution. (Bottom) ${ }^{37} \mathrm{Cs},{ }^{60} \mathrm{Co}$ and composite spectra of a bar-shaped detector. 
mated ${ }^{57} \mathrm{Co}$ beams incident on the negative electrode show the spatial resolution of the array to be characteristic of the dimensions of a detector element. Typical energy resolution of a detector element in the array is $10 \mathrm{keV}$ (FWHM) for ${ }^{57} \mathrm{Co}$. It is not unreasonable to extend this concept to larger volume elements to attain a single larger volume detector.

Rudimentary imaging was performed with this array. $A{ }^{57}$ Co source was viewed through a 16 hole $\mathrm{Pb}$ collimator. Count rates above $90 \mathrm{keV}$ for two of the four sections are plotted in figure 4 . The data are in good agreement with envelopes determined by scanning a single collimated detector through each of the four sections of the source. These results demonstrate rudimentary imaging with semiconductor detectors operated at room temperature. However, the poor yield and the necessity of arrays in a monolithic configuration to accommodate information processing presently prevents the economic construction of large area arrays for pratical use.

3.2 BAR-SHAPED DETECTORS. - An intermediate configuration between the plane parallel and hemis- pherical device is the bar-shaped detector. Such a detector provides a small frontal area for good spatial resolution and the necessary length for good stopping power. Such a geometry has been proposed for semiconductor probes [10] and should be useful for detector elements in CAT-scanners and reentry vehicles. Such detectors are especially important in the latter application where arrays of such detectors monitors the thickness of heat shields and nosetip changes [11]. Figure 5 shows the gamma ray spectrum from a $2 \mathrm{~cm} \times 3 \mathrm{~mm} \times 7 \mathrm{~mm}$ detector. Both ${ }^{137} \mathrm{Cs}$, ${ }^{60} \mathrm{Co}$ and composite spectra were taken. The counting efficiency of the ${ }^{137} \mathrm{Cs}$ photopeak for an energy threshold set in the valley between the photopeak and Compton edge was $80 \%$ of the theoretical number of photoevents occuring in that volume.

4. Summary. - There are several ways to improve the resolution and volume of $\mathrm{CdTe}$ detectors. Improved transport properties and uniformity are the most direct approach. However, further advances are possible by tailoring the detector geometry to the transport properties and photon energy at hand.

\section{References}

[1] Malm, H. L., Canali, C., Mayer, J. W., Nicolet, M.-A., Zanio, K. and Akutagawa, W., Appl. Phys. Lett. 26 (1975) 344

[2] Dabrowski, A. J., Chwaszczewska, J., IwanczK, J., Triboulet, R. and Marfaing, Y., IEEE Trans. Nucl. Sci. NS-23 (1976) 171 and Proc. Int. Symp. Cadmium Telluride Material Gamma Ray Detect., Strasbourg (1976).

[3] Zanio, K., Montano, H. and Krajenbrink, F., Appl. Phys. Lett. 27 (1975) 159.

[4] Zanio, K., Krajenbrink, F. and Montano, H., IEEE Trans. Nucl. Sci. NS-21 (1974) 315.

[5] Ottaviani, G., Canali, C. and Quaranta, A. A., IEEE Trans. Nucl. Sci. NS-22 (1975) 192.

[6] MAYer, J. W., in Semiconductor Detectors (G. Bertolini and A. Coche, eds.) p. 455 (North-Holland Publishing Co., Amsterdam).

[7] Siffert, P., Berger, J., Sharager, C., Cornet, A., Stuck, R., Bell, R. O., Serreze, H. B. and Wald, F. V., IEEE Trans. Nucl. Sci. NS-23 (1976) 159.

[8] Bell, R. O., Wald, F. V., Canali, C., Nava, F. and OtTAVIANI, G., IEEE Trans. Nucl. Sci. NS-21 (1974) 331.

[9] Alekseenko, M. V., Arkad'eva, E. N., Kisilenko, V. S., Maslova, L. V., Matveev, O. A., Prokof'ev, S. V., Ryvinin, S. M. and Khusainov, A. Kh., Fiz. Tekh. Poluprovodu 8 (1974) 550 (Engl. Transl. : Sov. Phys. Semicond. 8 351).

[10] Walford, G. V. and PARKer, R. P., IEEE Trans. Nucl. Sci. NS-20 (1973) 318.

[11] Droms, C. R., Langdon, W. R., Robison, A. G. and ENTINE, G., IEEE Trans. Nucl. Sci. NS-23 (1976) 498. 